\title{
Rancang Bangun Media Pembelajaran Praktik Alignment
}

\author{
Amrullah $^{1^{*}}$, Aminuddin $^{2}$ \\ ${ }^{1,2}$ Politeknik Bosowa, Makasar \\ *amrullah.mansyur@yahoo.com
}

\begin{abstract}
In fulfilling the achievement of learning, theories given by the instructor of course need to be supported by the existence of real practice in its application in the industry. In this research, it is expected that machine element can be better understood through training kit, can be formulated Standard Operational Procedure (SOP) of training kit and produced textbook as reference in alignment. The research method is designing, assembling and testing equipment. The research procedure undertaken is literature study by collecting and compiling data related to themes, field problems and solutions that can be used. The design is adjusted to the layout that can provide practical and ergonomic ease in the use of training kit. This design is simulated visually through solid work software for the determination of dimensions and materials used. Specification of electric motor used $1430 \mathrm{rpm}, 0.5 \mathrm{Hp} ; 220 \mathrm{~V} ; 3.16$ A; $50 \mathrm{~Hz}$. For support and reference in the process of learning alignment practice then after the testing process is done, can be produced Standard Operational Procedure (SOP) of training kit and textbooks. From this research can be concluded that the introduction of machine element can be better understood through training kit, the importance of Standard Operational Procedure (SOP) the use of instructional equipment so that the application of alignment can be delivered systematically, textbook as reference is the most important part of learning media.
\end{abstract}

Keywords : alignment, learning media, learning material

\begin{abstract}
Abstrak
Pada penelitian ini diharapkan elemen mesin dapat lebih dipahami melalui media pembelajaran, dapat dirumuskannya Standard Operational Procedure (SOP) penggunaan media pembelajaran dan dihasilkan buku ajar sebagai referensi dalam praktik alignment. Metode penelitian yang dilakukan adalah perancangan, perakitan dan pengujian peralatan. Prosedur penelitian yang dilakukan adalah studi literatur dengan mengumpulkan dan menyusun data - data terkait dengan tema, masalah-masalah di lapangan dan solusi yang dapat digunakan. Perancangan desain disesuaikan dengan layout yang dapat memberi kemudahan secara praktis dan ergonomis dalam penggunaan media pembelajaran. Desain ini disimulasikan secara visual melalui software solidwork untuk penentuan dimensi dan bahan yang digunakan. Spesifikasi motor listrik yang digunakan $1430 \mathrm{rpm}$, 0,5 Hp; 220 V; 3,16 A; 50 Hz.Sebagai penunjang dan referensi dalam proses pembelajaran praktik alignment maka setelah proses pengujian dilakukan, dapat dihasilkan Standard Operational Procedure (SOP) penggunaan media pembelajaran dan buku ajar. Dari penelitian ini dapat disimpulkan bahwa pengenalan elemen mesin dapat lebih dipahami melalui media pembelajaran, pentingnya Standard Operational Procedure (SOP) penggunaan media pembelajaran sehingga penerapan alignment dapat disampaikan secara sistematis, buku ajar sebagai referensi merupakan bagian terpenting dari media pembelajaran.
\end{abstract}

Kata kunci : alignment, media pembelajaran, bahan ajar

\section{Pendahuluan}

Telah banyak pendapat yang telah

diungkapkan para ahli mengenai media

pembelajaran bahwa media merupakan segala sesuatu yang dapat digunakan untuk menyalurkan pesan yang dapat merangsang pikiran, perasaan, perhatian dan kemauan siswa sehingga terjadi proses belajar (Ahmad, AKH, 2007) 
Alignment adalah suatu pekerjaan atau proses mensimetriskan kedua objek atau sumbu shaft sehingga sentris antara shaft penggerak dengan sumbu shaft yang digerakan dengan dua tumpuan saling berkaitan. Tetapi dalam kenyataannya pengertian lurus tidak bisa didapatkan 100\% sehingga harus diberikan toleransi kurang dari 0,05 mm, untuk mendapatkan kesentrisan antara kedua shaft pemutaran dan shaft yang diputar hingga tidak menimbulkan gesekan, getaran dan faktorfaktor lainnya. Penyimpangan yang terjadi dari keadaan alignment disebut misalignment. Penyimpangan yang tidak diizinkan (misalignment) terjadi antara sumbu poros penggerak dan sumbu poros yang digerakkan. Terjadinya misalignment dapat menyebabkan kerusakan pada komponen-komponen mesin yang berputar.

Dalam memenuhi capaian pembelajaran, teoriteori yang diberikan oleh para pengajar tentunya perlu didukung dengan adanya praktik nyata dalam penerapannya di dunia kerja kelak. Sama halnya dengan mata kuliah praktik alignment yang perlu didukung dengan pengadaan media pembelajaran alignment. Media pembelajaran diharapkan dapat mempermudah mahasiswa untuk memahami dan mempraktikkan metode-metode alignment secara langsung. Media pembelajaran ini akan sangat bermanfaat bagi mahasiswa Program Studi Perawatan dan Perbaikan Mesin, karena mahasiswa dapat menerapkan teori-teori yang dikhususkan pada mata kuliah praktik alignment.

Pada penelitian ini diharapkan elemen mesin dapat lebih dipahami melalui media pembelajaran, dapat dirumuskannya Standard Operational
Procedure (SOP) penggunaan media pembelajaran dan dihasilkan buku ajar sebagai referensi dalam praktik alignment.

\subsection{Kopling}

Kopling merupakan suatu elemen mesin yang berfungsi sebagai penerus putaran dan daya dari shaft penggerak ke shaft yang digerakkan secara pasti (tanpa slip) dimana sumbu kedua shaft tersebut terletak pada satu bidang lurus atau dapat sedikit berbeda sumbunya (Marzuki, Tejo dan Fianel, Armen., 2013). Kopling dibedakan menjadi dua tipe, yaitu kopling tetap dan kopling tidak tetap. Kopling tetap menghubungkan dua batang shaft secara tetap, tetapi kopling tidak tetap (clutch) dapat mudah menghubungkan dan memutuskan kembali hubungan tersebut antara dua batang shaft dalam keadaan berputar atau diam (Daryanto, 2012).

Sebelum memulai alignment kopling, kegiatan yang dilakukan adalah mengecek soft foot pada kaki-kaki motor dengan menggunakan dial indicator. Soft foot adalah kondisi kaki-kaki mesin tidak rata (cacat) atau bending.

\subsection{Puli-Sabuk}

Puli penggerak (driver pulley) menggerakkan sabuk dan untuk memutar puli yang digerakkan (driven pulley). Gesekan yang terjadi antara puli dan sabuk ditimbulkan oleh gaya yang bekerja dalam kedua bagian puli (Stolk Jac, Kros, C. c., 1981).

Sabuk dan puli adalah suatu elemen mesin yang berfungsi untuk memindahkan putaran atau daya dari shaft penggerak ke shaft yang digerakkan dengan kecepatan yang sama atau berbeda. Hal yang menentukan besar daya yang ditransmisikan 
adalah kecepatan sabuk, kekencangan sabuk, sudut kontak antara sabuk dan puli serta kondisi dimana sabuk digunakan. Sedangkan koefisien gesek antara sabuk dan puli tergantung pada bahan sabuk, bahan puli dan kecepatan sabuk.

\subsection{Sprocket dan rantai}

Sprocket dan rantai merupakan elemen mesin transmisi yang biasa digunakan pada mesin yang memerlukan putaran tanpa slip. Karena elemen ini dilengkapi dengan gigi-gigi pada sproket yang memutar rantai rol. Elemen pemindah putaran ini berdeda dengan sabuk dan puli yang dapat slip pada saat berputar satu sama lain. Rantai tidak dapat slip, karena itu rantai tidak memerlukan tegangan awal, sehingga shaft dan blok bantalan tidak mengalami beban ekstra.

\subsection{Roda Gigi}

Roda gigi adalah bagian dari mesin yang berputar yang berguna untuk mentransmisikan daya. Roda gigi memiliki gigi-gigi yang saling bersinggungan dengan gigi dari roda gigi yang lain. Dua atau lebih roda gigi yang bersinggungan dan bekerja bersama-sama disebut sebagai transmisi roda gigi dan bisa menghasilkan keuntungan mekanis melalui rasio jumlah gigi. Roda gigi mampu mengubah kecepatan putar, torsi dan arah daya terhadap sumber daya. Tidak semua roda gigi berhubungan dengan roda gigi yang lain.

Dalam pemasangan roda gigi harus dilakukan alignment untuk menghindari kerusakan mesin dan pasangan roda gigi itu sendiri. Roda gigi dapat mengalami kerusakan berupa patah gigi keausan atau berlubang-lubang permukaannya dan tergores permukaannya karena pecahnya selaput minyak pelumas, biasanya kekuatan gigi terhadap lenturan

dan tekanan permukaan merupakan hal yang terpenting untuk diperhatikan

\section{Metoda Penelitian}

Metoda penelitian yang dilakukan adalah perancangan, perakitan dan pengujian peralatan. Prosedur penelitian yang dilakukan adalah studi literatur dengan mengumpulkan dan menyusun data-data terkait dengan tema, masalah-masalah di lapangan dan solusi yang dapat digunakan. Perancangan desain disesuaikan dengan layout yang dapat memberi kemudahan secara praktis dan ergonomis dalam penggunaan media pembelajaran seperti yang ditunjukkan pada gambar 1. Desain ini disimulasikan secara visual melalui software solidwork untuk penentuan dimensi dan bahan yang digunakan. Spesifikasi motor listrik yang digunakan $1430 \mathrm{rpm}, 0,5 \mathrm{Hp} ; 220 \mathrm{~V} ; 3,16 \mathrm{~A} ; 50$ Hz.

Sebagai penunjang dan referensi dalam proses pembelajaran praktik alignment maka setelah proses pengujian dilakukan, dapat dihasilkan Standard Operational Procedure (SOP) dan buku ajar. 


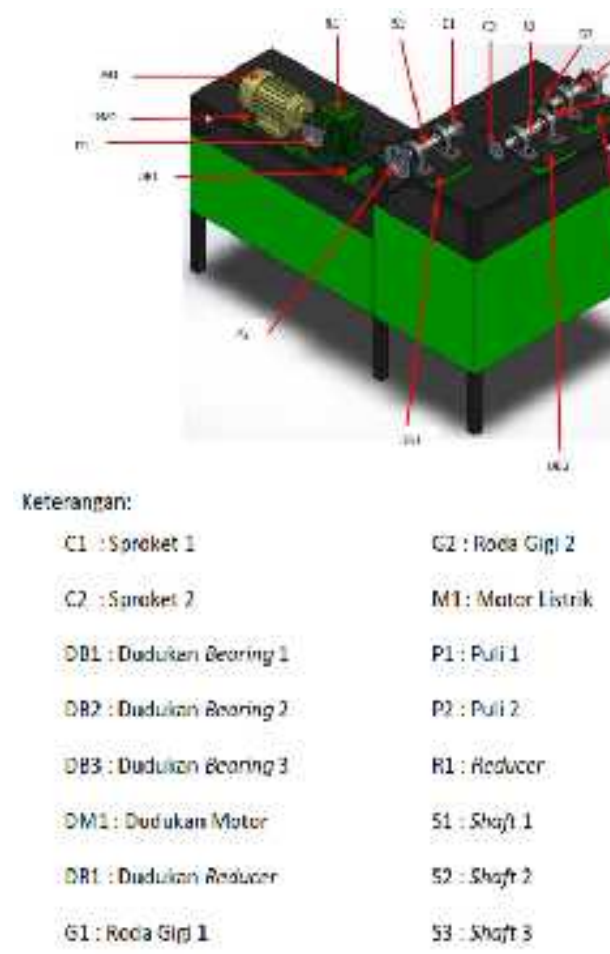

Gambar 1. Desain Media Pembelajaran Alignment

\section{Hasil Penelitian}

Hasil dari penelitian ini berupa SOP penggunaan media pembelajaran dan buku ajar seperti ditunjukkan pada gambar 2 .

\section{Standard Operational Procedure (SOP) Penggunaan Media Pembelajaran}

\section{1) Alignment Kopling}

a. Pasang dudukan reducer kemudian kencangkan bautnya.

b. Pasang reducer pada dudukannya kemudian lakukan leveling menggunakan waterpass dan feeler gauge.

c. Pasang dudukan motor kemudian kencangkan bautnya.

d. Periksa soft foot pada kaki motor.

e. Buka pasak dari shaft motor dan input shaft reducer. f. Pasang kopling pada shaft motor dan input shaft reducer, kemudian pasang masingmasing pasaknya menggunakan palu lunak.

g. Kencangkan baut pengancing (setscrew) agar kopling tetap pada posisinya kemudian rapatkan keduanya.

h. Lakukan pengukuran untuk mengetahui besar penyimpangan yang terjadi. Gunakan waterpass dan feeler gauge untuk mengukur kemiringan, kemudian gambar sketsa penyimpangan yang terjadi dan tentukan kebutuhan shim plat.

i. Kencangkan baut kaki motor.

j. Periksa kembali kopling untuk memastikan alignment benar-benar telah didapatkan.

k. Hubungkan sumber listrik utama pada panel listrik. Tekan tombol on untuk menghidupkan motor penggerak, dan amati jalannya sistem penggerak.

1. Matikan motor penggerak dengan menekan tombol off.

\section{2) Alignment Puli dan Sabuk}

a. Pasang dudukan bearing 1 kemudian kencangkan bautnya.

b. Pasang puli A1x3,5" pada output shaft reducer.

c. Lakukan leveling terhadap poros referensi. Gunakan waterpass dan feeler gauge.

d. Pasang Shaft 1 pada dua bearing kemudian pasang pada dudukan bearing.

e. Pasang baut dan mur bearing.

f. Pasang puli A1x5" pada shaft 1 .

g. Lakukan leveling terhadap poros yang akan disetel. Gunakan waterpass dan feeler gauge. 
h. Pasang sabuk penggerak (V-belt) pada puli yang sesuai dengan jarak pemasangan. Hindari pemaksaan pada saat memasang sabuk penggerak untuk mencegah kerusakan.

i. Tegangkan kondisi sabuk dengan menyetel posisi baut bearing depan kemudian kencangkan baut kanan.

j. Kalibrasi angular misalignment

k. Kalibrasi offset misalignment

1. Periksa kembali puli dan sabuk untuk memastikan alignment benar-benar telah didapatkan.

m. Hubungkan sumber listrik utama pada panel listrik. Tekan tombol on untuk menghidupkan motor penggerak, dan amati jalannya sistem penggerak.

n. Matikan motor penggerak dengan menekan tombol off.

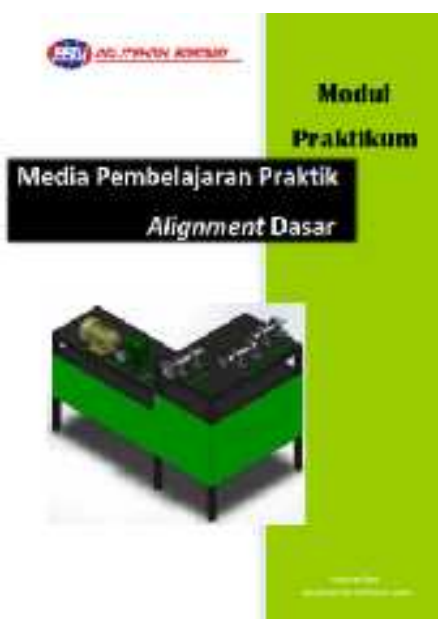

Gambar 2. Buku ajar media pembelajaran praktik alignment

\section{Kesimpulan}

Dari hasil pengujian dapat diambil beberapa kesimpulan sebagai berikut.

1. Pengenalan elemen mesin dapat lebih dipahami melalui media pembelajaran.

2. Pentingnya Standard Operational Procedure (SOP) penggunaan media pembelajaran sehingga penerapan alignment dapat disampaikan secara sistematis.

3. Buku ajar sebagai referensi merupakan bagian terpenting dari media pembelajaran.

\section{Saran}

Pemakaian media pembelajaran ini harus mengikuti Standard Operational Procedure (SOP) agar mengifisienkan waktu dalam pemasangannya dan kondisi alignment mudah didapatkan.

\section{Daftar Pustaka}

Ahmad, AKH.(2007). Media Pembelajaran. Makassar: Universitas Negeri Makassar .

Marzuki, Tejo dan Fianel, Armen. (2013). Buku Tabel Teknik Mesin. Malang: Gunung Samudera

Daryanto. (2012). Dasar-Dasar Teknik Mesin. Jakarta: Rineka Cipta

Stolk Jac, Kros, C. c.(1981). Elemen Mesin, Elemen Konstruksi dari Bangunan Mesin (E ke 21). Jakarta: Erlangga 